\title{
Generalized Ulam - Hyers Stability of Derivations of a AQ - Functional Equation
}

\author{
M. Arunkumar \\ Government Arts College, \\ Department Of Mathematics, \\ Tiruvannamalai - 606 603, Tamilnadu, India. \\ annarun2002@yahoo.co.in
}

\begin{abstract}
In this paper, the author established the generalized Ulam - Hyers stability of Derivations of additive and quadratic (AQ)- functional equation

$$
f(x+y)+f(x-y)=2 f(x)+f(y)+f(-y)
$$

\section{RESUMEN}

En este artículo el autor establece la estabilidad generalizada Ulam-Hyers de derivaciones de la ecuación (AQ)-funcional cuadrática y aditiva

$$
f(x+y)+f(x-y)=2 f(x)+f(y)+f(-y)
$$

Keywords and Phrases: Additive functional equations, Quadratic functional equation, Mixed type functional equation, Additive derivations, Quadratic derivations, Ulam - Hyers stability

2010 AMS Mathematics Subject Classification: 39B52, 32B72, 32B82 


\section{Introduction}

The study of stability problems for functional equations is related to a question of Ulam 33. concerning the stability of group homomorphisms and affirmatively answered for Banach spaces by Hyers [13. It was further generalized and excellent results obtained by number of authors [2, 10, 24, 30, 32,

Over the last six or seven decades, the above problem was tackled by numerous authors and its solutions via various forms of functional equations like additive, quadratic, cubic, quartic, mixed type functional equations which involves only these types of functional equations were discussed. We refer the interested readers for more information on such problems to the monographs [1, 9, 14, 19, 22, 31].

C. Park 25] applied Gavruta's result to Banach modules over a $\mathrm{C}^{*}$-algebra. Many authors have studied the structure of $\mathrm{C}^{*}$ - algebras for different types of functional equations in various settings one can refer [6, 8, 26, 28. It seems that approximate derivations was first investigated by K.W. Jun and D.W. Park [16]. Recently, the stability of derivations have been investigated in 17, 11, 12, 20, 27, 29] and references therein. The stability of cubic derivations was first time introduced and investigated by M.E. Gordji et. al.,[12]. With the help of [12, the stability of quadratic derivations was discussed by M. Arunkumar et. al., 3.

Very recently M. Arunkumar and J.M. Rassias [5], established the generalized Ulam - Hyers stability of an additive and quadratic (AQ)-mixed type functional equation

$$
f(x+y)+f(x-y)=2 f(x)+f(y)+f(-y)
$$

in Banach spaces. The solution and stability of several types of Mixed type additive and quadratic type functional equations were discussed in $4,17,18,21,23$,

In this paper, the author first time established the generalized Ulam - Hyers stability of mixed derivations of a additive - quadratic (AQ)- functional equation (1).

Hereafter through out this paper, let us consider $X$ and $Y$ to be a normed Algebra and a Banach Algebra, respectively.

\section{Stability Results: Additive Derivations}

In this section, the authors investigate the generalized Ulam-Hyers stability of additive derivations of the AQ-functional equation (1).

Definition 2.1. A $\mathbb{C}$-linear mapping $\mathrm{A}: \mathrm{X} \rightarrow \mathrm{X}$ is called Additive Derivation on $\mathrm{X}$ if $\mathrm{A}$ satisfies

$$
A(x y)=A(x) y+x A(y)
$$

for all $\mathrm{x}, \mathrm{y} \in \mathrm{X}$. 
Theorem 2.1. Let $\mathfrak{j}= \pm 1$. Let $\mathrm{f}_{\mathrm{a}}: \mathrm{X} \rightarrow \mathrm{Y}$ be a odd mapping for which there exist a function $\alpha, \beta: X^{2} \rightarrow[0, \infty)$ with the condition

$$
\begin{aligned}
& \sum_{n=0}^{\infty} \frac{\alpha\left(2^{n j} x, 2^{n j} y\right)}{2^{n j}} \text { converges in } \mathbb{R} \text { and } \lim _{n \rightarrow \infty} \frac{\alpha\left(2^{n j} x, 2^{n j} y\right)}{2^{n j}}=0 \\
& \sum_{n=0}^{\infty} \frac{\beta\left(2^{n j} x, 2^{n j} y\right)}{2^{2 n j}} \text { converges in } \mathbb{R} \text { and } \lim _{n \rightarrow \infty} \frac{\alpha\left(2^{n j} x, 2^{n j} y\right)}{2^{2 n j}}=0
\end{aligned}
$$

such that the functional inequalities

$$
\left\|f_{a}(x+y)+f_{a}(x-y)-2 f_{a}(x)-f_{a}(y)-f_{a}(-y)\right\| \leq \alpha(x, y)
$$

and

$$
\left\|f_{a}(x y)-f_{a}(x) y-x f_{a}(y)\right\| \leq \beta(x, y)
$$

for all $\mathrm{x}, \mathrm{y} \in \mathrm{X}$. Then there exists a unique Additive Derivation mapping $\mathrm{A}: \mathrm{X} \rightarrow \mathrm{Y}$ satisfying the functional equation (1) and

$$
\left\|f_{a}(x)-A(x)\right\| \leq \frac{1}{2} \sum_{k=\frac{1-j}{2}}^{\infty} \frac{\alpha\left(2^{k j} x, 2^{k j} x\right)}{2^{k j}}
$$

for all $\mathrm{x} \in \mathrm{X}$. The mapping $\mathrm{A}(\mathrm{x})$ is defined by

$$
A(x)=\lim _{n \rightarrow \infty} \frac{f_{a}\left(2^{n j} x\right)}{2^{n j}}
$$

for all $\mathrm{x} \in \mathrm{X}$.

Proof. Assume $j=1$. Replacing $y$ by $x$ in (4) and using oddness of $f$, we get

$$
\left\|f_{a}(x)-\frac{f_{a}(2 x)}{2}\right\| \leq \frac{\alpha(x, x)}{2}
$$

for all $x \in X$. Now replacing $x$ by $2 x$ and dividing by 2 in (8), we get

$$
\left\|\frac{f_{a}(2 x)}{2}-\frac{f_{a}\left(2^{2} x\right)}{2^{2}}\right\| \leq \frac{\alpha(2 x, 2 x)}{2^{2}}
$$

for all $x \in X$. From (8) and (9), we obtain

$$
\begin{aligned}
\left\|f_{a}(x)-\frac{f_{a}\left(2^{2} x\right)}{2^{2}}\right\| & \leq\left\|f_{a}(x)-\frac{f_{a}(2 x)}{2}\right\|+\left\|\frac{f_{a}(2 x)}{2}-\frac{f_{a}\left(2^{2} x\right)}{2^{2}}\right\| \\
& \leq \frac{1}{2}\left[\alpha(x, x)+\frac{\alpha(2 x, 2 x)}{2}\right]
\end{aligned}
$$


for all $x \in X$. In general for any positive integer $n$, we get

$$
\begin{aligned}
\left\|f_{a}(x)-\frac{f_{a}\left(2^{n} x\right)}{2^{n}}\right\| & \leq \frac{1}{2} \sum_{k=0}^{n-1} \frac{\alpha\left(2^{k} x, 2^{k} x\right)}{2^{k}} \\
& \leq \frac{1}{2} \sum_{k=0}^{\infty} \frac{\alpha\left(2^{k} x, 2^{k} x\right)}{2^{k}}
\end{aligned}
$$

for all $x \in X$. In order to prove the convergence of the sequence

$$
\left\{\frac{f_{a}\left(2^{n} x\right)}{2^{n}}\right\}
$$

replace $x$ by $2^{m} x$ and dividing by $2^{m}$ in (11), for any $m, n>0$, we deduce

$$
\begin{aligned}
\left\|\frac{f_{a}\left(2^{m} x\right)}{2^{m}}-\frac{f_{a}\left(2^{n+m} x\right)}{2^{(n+m)}}\right\| & =\frac{1}{2^{m}}\left\|f_{a}\left(2^{m} x\right)-\frac{f_{a}\left(2^{n} \cdot 2^{m} x\right)}{2^{n}}\right\| \\
& \leq \frac{1}{2} \sum_{k=0}^{n-1} \frac{\alpha\left(2^{k+m} x, 2^{k+m} x\right)}{2^{k+m}} \\
& \leq \frac{1}{2} \sum_{k=0}^{\infty} \frac{\alpha\left(2^{k+m} x, 2^{k+m} x\right)}{2^{k+m}} \\
& \rightarrow 0 \text { as } m \rightarrow \infty
\end{aligned}
$$

for all $x \in X$. Hence the sequence $\left\{\frac{f_{a}\left(2^{n} x\right)}{2^{n}}\right\}$ is Cauchy sequence. Since $Y$ is complete, there exists a mapping $A: X \rightarrow Y$ such that

$$
A(x)=\lim _{n \rightarrow \infty} \frac{f_{a}\left(2^{n} x\right)}{2^{n}} \forall x \in X .
$$

Letting $n \rightarrow \infty$ in (11) we see that (6) holds for all $x \in X$. To prove that $A$ satisfies (11), replacing $(x, y)$ by $\left(2^{n} x, 2^{n} y\right)$ and dividing by $2^{n}$ in (4), we obtain

$$
\frac{1}{2^{n}}\left\|f_{a}\left(2^{n} x+2^{n} y\right)+f_{a}\left(2^{n} x-2^{n} y\right)-2 f_{a}\left(2^{n} x\right)+f_{a}\left(2^{n} y\right)+f_{a}\left(-2^{n} y\right)\right\| \leq \frac{1}{2^{n}} \alpha\left(2^{n} x, 2^{n} y\right)
$$

for all $x, y \in X$. Letting $n \rightarrow \infty$ in the above inequality and using the definition of $A(x)$, we see that

$$
A(x+y)+A(x-y)=2 A(x)+A(y)+A(-y)
$$

Hence $A$ satisfies (11) for all $x, y \in X$. It follows from (5) that

$$
\begin{aligned}
\| A(x y)- & A(x) y-x A(y) \| \\
& =\frac{1}{2^{2 n}}\left\|f_{a}\left(2^{n}(x y)\right)-f_{a}\left(2^{n} x\right)\left(2^{n} y\right)-\left(2^{n} x\right) f_{a}\left(2^{n} y\right)\right\| \\
& \leq \frac{1}{2^{n}} \beta\left(2^{n} x, 2^{n} y\right) \\
& \rightarrow 0 \text { as } n \rightarrow \infty
\end{aligned}
$$


for all $x, y \in X$. To prove that $A$ is unique, let $B(x)$ be another mapping satisfying (11) and (6), then

$$
\begin{aligned}
\|A(x)-B(x)\| & =\frac{1}{2^{n}}\left\|A\left(2^{n} x\right)-B\left(2^{n} x\right)\right\| \\
& \leq \frac{1}{2^{n}}\left\{\left\|A\left(2^{n} x\right)-f_{a}\left(2^{n} x\right)\right\|+\left\|f_{a}\left(2^{n} x\right)-B\left(2^{n} x\right)\right\|\right\} \\
& \leq \sum_{k=0}^{\infty} \frac{\alpha\left(2^{k+n} x, 2^{k+n} x\right)}{2^{(k+n)}} \\
& \rightarrow 0 \text { as } n \rightarrow \infty
\end{aligned}
$$

for all $x \in X$. Hence $A$ is unique. Thus the mapping $A: X \rightarrow Y$ is a unique Additive Derivation mapping satisfying (6).

For $\mathfrak{j}=-1$, we can prove a similar stability result. This completes the proof of the theorem.

The following Corollary is an immediate consequence of Theorem 2.1 concerning the stability of (11).

Corollary 2.2. Let $\mathrm{f}_{\mathrm{a}}: \mathrm{X} \rightarrow \mathrm{Y}$ be a odd mapping and there exists real numbers $\lambda$ and $\mathrm{s}$ such that

$$
\begin{aligned}
& \left\|f_{a}(x+y)+f_{a}(x-y)-2 f_{a}(x)-f_{a}(y)-f_{a}(-y)\right\| \\
& \leq\left\{\begin{array}{lll}
\lambda, & \\
\lambda\left\{\|x\|^{s}+\|y\|^{s}\right\}, & s<1 \quad \text { or } \quad s>1 ; \\
\lambda\|x\|^{s}\|y\|^{s}, & s<\frac{1}{2} \quad \text { or } \quad s>\frac{1}{2} \\
\lambda\left\{\|x\|^{s}\|y\|^{s}+\left\{\|x\|^{2 s}+\|y\|^{2 s}\right\}\right\}, & s<\frac{1}{2} \quad \text { or } \quad s>\frac{1}{2}
\end{array}\right. \\
& \left\|f_{a}(x y)-f_{a}(x) y-x f_{a}(y)\right\| \\
& \leq \begin{cases}\lambda, & \\
\lambda\left\{\|x\|^{s}+\|y\|^{s}\right\}, & s<1 \quad \text { or } \quad s>1 ; \\
\lambda\|x\|^{s}\|y\|^{s}, & s<\frac{1}{2} \quad \text { or } \quad s>\frac{1}{2} \\
\lambda\left\{\|x\|^{s}\|y\|^{s}+\left\{\|x\|^{2 s}+\|y\|^{2 s}\right\}\right\}, & s<\frac{1}{2} \quad \text { or } \quad s>\frac{1}{2}\end{cases}
\end{aligned}
$$

for all $\mathrm{x}, \mathrm{y} \in \mathrm{X}$. Then there exists a unique Additive Derivation function $\mathrm{A}: \mathrm{X} \rightarrow \mathrm{Y}$ such that

$$
\left\|f_{a}(x)-A(x)\right\| \leq\left\{\begin{array}{l}
\lambda, \\
\frac{2 \lambda\|x\|^{s}}{\left|2-2^{s}\right|}, \\
\frac{\lambda\|x\|^{2 s}}{\left|2-2^{2 s}\right|} \\
\frac{3 \lambda\|x\|^{2 s}}{\left|2-2^{2 s}\right|}
\end{array}\right.
$$

for all $x \in X$. 


\section{Stability Results: Quadratic Derivations}

In this section, the author establish the generalized Ulam-Hyers stability of quadratic derivations of the AQ-functional equation (1).

Definition 3.1. Quadratic Derivation. A $\mathbb{C}$-linear mapping $\mathrm{Q}: \mathrm{X} \rightarrow \mathrm{X}$ is called Quadratic Derivation on $\mathrm{X}$ if $\mathrm{Q}$ satisfies

$$
\mathrm{Q}(x y)=\mathrm{Q}(x) y^{2}+x^{2} \mathrm{Q}(\mathrm{y})
$$

for all $\mathrm{x}, \mathrm{y} \in \mathrm{X}$.

Theorem 3.1. Let $\mathrm{j}= \pm 1$. Let $\mathrm{f}_{\mathrm{q}}: \mathrm{X} \rightarrow \mathrm{Y}$ be a even mapping for which there exist a function $\alpha, \beta: X^{2} \rightarrow[0, \infty)$ with the condition

$$
\begin{aligned}
& \sum_{n=0}^{\infty} \frac{\alpha\left(2^{n j} x, 2^{n j} y\right)}{2^{2 n j}} \text { converges in } \mathbb{R} \text { and } \lim _{n \rightarrow \infty} \frac{\alpha\left(2^{n j} x, 2^{n j} y\right)}{2^{2 n j}}=0 \\
& \sum_{n=0}^{\infty} \frac{\beta\left(2^{n j} x, 2^{n j} y\right)}{2^{4 n j}} \text { converges in } \mathbb{R} \text { and } \lim _{n \rightarrow \infty} \frac{\beta\left(2^{n j} x, 2^{n j} y\right)}{2^{4 n j}}=0
\end{aligned}
$$

such that the functional inequalities

$$
\left\|f_{q}(x+y)+f_{q}(x-y)-2 f_{q}(x)-f_{q}(y)-f_{q}(-y)\right\| \leq \alpha(x, y)
$$

and

$$
\left\|f_{q}(x y)-x^{2} f_{q}(y)-f_{q}(x) y^{2}\right\| \leq \beta(x, y)
$$

for all $\mathrm{x}, \mathrm{y} \in \mathrm{X}$. Then there exists a unique Quadratic Derivation mapping $\mathrm{Q}: \mathrm{X} \rightarrow \mathrm{Y}$ satisfying the functional equation (1) and

$$
\left\|f_{q}(x)-Q(x)\right\| \leq \frac{1}{4} \sum_{k=\frac{1-j}{2}}^{\infty} \frac{\alpha\left(2^{k j} x, 2^{k j} x\right)}{2^{2 k j}}
$$

for all $\mathrm{x} \in \mathrm{X}$. The mapping $\mathrm{Q}(\mathrm{x})$ is defined by

$$
Q(x)=\lim _{n \rightarrow \infty} \frac{f_{q}\left(2^{n j} x\right)}{2^{2 n j}}
$$

for all $x \in X$.

Proof. It follows from (5) that

$$
\begin{aligned}
\| Q(x y)- & x^{2} Q(y)-Q(x) y^{2} \| \\
& =\frac{1}{2^{4 n}}\left\|f_{q}\left(2^{n}(x y)\right)-\left(2^{n} x\right)^{2} f_{q}\left(2^{n} y\right)-f_{q}\left(2^{n} x\right)\left(2^{n} y\right)^{2}\right\| \\
& \leq \frac{1}{2^{4 n}} \beta\left(2^{n} x, 2^{n} y\right) \\
& \rightarrow 0 \text { as } n \rightarrow \infty
\end{aligned}
$$


for all $x, y \in X$. The rest of the proof is similar tracing to that of Theorem 2.1. Thus the mapping $\mathrm{Q}: \mathrm{X} \rightarrow \mathrm{Y}$ is a unique Quadratic Derivation mapping satisfying (6).

The following Corollary is an immediate consequence of Theorem 3.1 concerning the stability of (1).

Corollary 3.2. Let $\mathrm{f}_{\mathrm{q}}: \mathrm{X} \rightarrow \mathrm{Y}$ be a even mapping and there exists real numbers $\lambda$ and $\mathrm{s}$ such that

$$
\begin{aligned}
& \left\|f_{q}(x+y)+f_{q}(x-y)-2 f_{q}(x)-f_{q}(y)-f_{q}(-y)\right\| \\
& \leq\left\{\begin{array}{lll}
\lambda, & & \\
\lambda\left\{\|x\|^{s}+\|y\|^{s}\right\}, & s<2 & \text { or } \quad s>2 ; \\
\lambda\|x\|^{s}\|y\|^{s}, & s<1 & \text { or } \quad s>1 ; \\
\lambda\left\{\|x\|^{s}\|y\|^{s}+\left\{\|x\|^{2 s}+\|y\|^{2 s}\right\}\right\}, & s<1 & \text { or } \quad s>1 ;
\end{array}\right. \\
& \left\|f_{q}(x y)-x^{2} f_{q}(y)-f_{q}(x) y^{2}\right\| \\
& \leq\left\{\begin{array}{lll}
\lambda, & \\
\lambda\left\{\|x\|^{s}+\|y\|^{s}\right\}, & s<2 & \text { or } s>2 ; \\
\lambda\|x\|^{s}\|y\|^{s}, & s<1 & \text { or } s>1 ; \\
\lambda\left\{\|x\|^{s}\|y\|^{s}+\left\{\|x\|^{2 s}+\|y\|^{2 s}\right\}\right\}, & s<1 & \text { or } s>1 ;
\end{array}\right.
\end{aligned}
$$

for all $\mathrm{x}, \mathrm{y} \in \mathrm{X}$. Then there exists a unique quadratic Deviation function $\mathrm{Q}: \mathrm{X} \rightarrow \mathrm{Y}$ such that

$$
\left\|f_{q}(x)-Q(x)\right\| \leq\left\{\begin{array}{l}
\frac{\lambda}{3}, \\
\frac{2 \lambda\|x\|^{s}}{\left|4-2^{s}\right|} \\
\frac{\lambda\|x\|^{2 s}}{\left|4-2^{2 s}\right|} \\
\frac{3 \lambda\|x\|^{2 s}}{\left|4-2^{2 s}\right|}
\end{array}\right.
$$

for all $\chi \in X$

\section{Stability Results: Mixed Derivations}

In this section, the author present the generalized Ulam-Hyers stability of mixed derivations of the AQ-functional equation (1).

Theorem 4.1. Let $\mathrm{j}= \pm 1$. Let $\mathrm{f}: \mathrm{X} \rightarrow \mathrm{Y}$ be a odd mapping for which there exist a function $\alpha, \beta: X^{2} \rightarrow[0, \infty)$ with the conditions (2), (3), (2) and (3) such that the functional inequalities

$$
\|f(x+y)+f(x-y)-2 f(x)-f(y)-f(-y)\| \leq \alpha(x, y)
$$


(5) and (5) for all $\mathrm{x}, \mathrm{y} \in \mathrm{X}$. Then there exists a unique Additive Derivation mapping $\mathrm{A}: \mathrm{X} \rightarrow \mathrm{Y}$ and a unique Quadratic Derivation mapping $\mathrm{Q}: \mathrm{X} \rightarrow \mathrm{Y}$ satisfying the functional equation (1) and

$$
\begin{aligned}
\|f(x)-A(x)-Q(x)\| \leq \frac{1}{2} & \frac{1}{2} \sum_{k=\frac{1-j}{2}}^{\infty}\left(\frac{\alpha\left(2^{k j} x, 2^{k j} x\right)}{2^{k j}}+\frac{\alpha\left(-2^{k j} x,-2^{k j} x\right)}{2^{k j}}\right) \\
& \left.+\frac{1}{4} \sum_{k=\frac{1-j}{2}}^{\infty}\left(\frac{\alpha\left(2^{k j} x, 2^{k j} x\right)}{2^{2 k j}}+\frac{\alpha\left(-2^{k j} x,-2^{k j} x\right)}{2^{2 k j}}\right)\right]
\end{aligned}
$$

for all $\mathrm{x} \in \mathrm{X}$. The mapping $\mathrm{A}(\mathrm{x})$ and $\mathrm{Q}(\mathrm{x})$ are defined in (6) and (6) respectively for all $\mathrm{x} \in \mathrm{X}$.

Proof. Let $f_{o}(x)=\frac{f_{a}(x)-f_{a}(-x)}{2}$ for all $x \in X$. Then $f_{o}(0)=0$ and $f_{o}(-x)=-f_{o}(x)$ for all $x \in X$. Hence

$$
\left\|f_{o}(x+y)+f_{o}(x-y)-2 f_{o}(x)-f_{o}(y)-f_{o}(-y)\right\| \leq \frac{\alpha(x, y)}{2}+\frac{\alpha(-x,-y)}{2}
$$

By Theorem 2.1, we have

$$
\left\|f_{o}(x)-A(x)\right\| \leq \frac{1}{4} \sum_{k=\frac{1-j}{2}}^{\infty}\left(\frac{\alpha\left(2^{k j} x, 2^{k j} x\right)}{2^{k j}}+\frac{\alpha\left(-2^{k j} x,-2^{k j} x\right)}{2^{k j}}\right)
$$

for all $x \in X$. Also, let $f_{e}(x)=\frac{f_{q}(x)+f_{q}(-x)}{2}$ for all $x \in X$. Then $f_{e}(0)=0$ and $f_{e}(-x)=f_{e}(x)$ for all $x \in X$. Hence

$$
\left\|f_{e}(x+y)+f_{e}(x-y)-2 f_{e}(x)-f_{e}(y)-f_{e}(-y)\right\| \leq \frac{\alpha(x, y)}{2}+\frac{\alpha(-x,-y)}{2}
$$

By Theorem 3.1, we have

$$
\left\|f_{e}(x)-Q(x)\right\| \leq \frac{1}{8} \sum_{k=\frac{1-j}{2}}^{\infty}\left(\frac{\alpha\left(2^{k j} x, 2^{k j} x\right)}{2^{2 k j}}+\frac{\alpha\left(-2^{k j} x,-2^{k j} x\right)}{2^{2 k j}}\right)
$$

for all $x \in X$. Define

$$
f(x)=f_{e}(x)+f_{o}(x)
$$

for all $x \in X$. From (4), (6) and (7), we arrive

$$
\begin{aligned}
\|f(x)-A(x)-Q(x)\| & =\left\|f_{e}(x)+f_{o}(x)-A(x)-Q(x)\right\| \\
\leq & \left\|f_{o}(x)-A(x)\right\|+\left\|f_{e}(x)-Q(x)\right\| \\
\leq & \frac{1}{4} \sum_{k=\frac{1-j}{2}}^{\infty}\left(\frac{\alpha\left(2^{k j} x, 2^{k j} x\right)}{2^{k j}}+\frac{\alpha\left(-2^{k j} x,-2^{k j} x\right)}{2^{k j}}\right) \\
& +\frac{1}{8} \sum_{k=\frac{1-j}{2}}^{\infty}\left(\frac{\alpha\left(2^{k j} x, 2^{k j} x\right)}{2^{2 k j}}+\frac{\alpha\left(-2^{k j} x,-2^{k j} x\right)}{2^{2 k j}}\right)
\end{aligned}
$$

for all $x \in X$. Hence the theorem is proved. 
Using Corollaries 2.2 and 3.2 we have the following Corollary concerning the stability of (11).

Corollary 4.1. Let $\mathrm{f}: \mathrm{X} \rightarrow \mathrm{Y}$ be a mapping and there exits real numbers $\lambda$ and $\mathrm{s}$ such that

$$
\begin{aligned}
& \|f(x+y)+f(x-y)-2 f(x)-f(y)-f(-y)\| \\
& \quad \leq\left\{\begin{array}{lll}
\lambda, & \left.s<1\|x\|^{s}+\|y\|^{s}\right\}, & \text { or } \quad s>1 ; \\
\lambda\|x\|^{s}\|y\|^{s}, & s<\frac{1}{2} \text { or } \quad s>\frac{1}{2} \\
\lambda\left\{\|x\|^{s}\|y\|^{s}+\left\{\|x\|^{2 s}+\|y\|^{2 s}\right\}\right\}, & s<\frac{1}{2} \text { or } s>\frac{1}{2} ;
\end{array}\right.
\end{aligned}
$$

and (13), (9) for all $\mathrm{x}, \mathrm{y} \in \mathrm{X}$. Then there exists a unique Additive Deviation function $\mathrm{A}: \mathrm{X} \rightarrow \mathrm{Y}$ and a unique quadratic Deviation function $\mathrm{Q}: \mathrm{X} \rightarrow \mathrm{Y}$ such that

$$
\|f(x)-A(x)-Q(x)\| \leq\left\{\begin{array}{l}
\lambda\left(1+\frac{1}{3}\right), \\
2 \lambda\left(\frac{1}{\left|2-2^{s}\right|}+\frac{1}{\left|4-2^{s}\right|}\right)\|x\|^{s}, \\
\lambda\left(\frac{1}{\left|2-2^{2 s}\right|}+\frac{1}{\left|4-2^{2 s}\right|}\right)\|x\|^{2 s}, \\
3 \lambda\left(\frac{1}{\left|2-2^{2 s}\right|}+\frac{1}{\left|4-2^{2 s}\right|}\right)\|x\|^{2 s}
\end{array}\right.
$$

for all $\mathrm{x} \in \mathrm{X}$.

$$
\text { Received: December 2012. Revised: February } 2013 .
$$

\section{References}

[1] J. Aczel and J. Dhombres, Functional Equations in Several Variables, Cambridge Univ, Press, 1989.

[2] T. Aoki, On the stability of the linear transformation in Banach spaces, J. Math. Soc. Japan, 2 (1950), 64-66.

[3] M. Arunkumar, S. Jayanthi, S. Hema Latha, Stability of quadratic derivations of Arunquadratic functional equation, International Journal Mathematical Sciences and Engineering Applications, Vol. 5 No. V, Sept. 2011, 433-443.

[4] M. Arunkumar, S. Karthikeyan, Solution and stability of $\mathbf{n}$-dimensional mixed Type additive and quadratic functional equation, Far East Journal of Applied Mathematics, Volume 54, Number 1, 2011, 47-64.

[5] M. Arunkumar, John M. Rassias, On the generalized Ulam-Hyers stability of an AQmixed type functional equation with counter examples, Far East Journal of Applied Mathematics Volume 71, No. 2, (2012), 279-305. 
[6] C. Baak, D. Boo, Th.M. Rassias, Generalized additive mapping in Banach modules and isomorphism between $C^{*}$-algebras, J. Math. Anal. Appl. 314, (2006), 150-161.

[7] R. Badora, On approximate derivations, Math. Inequal. Appl. 9 (2006), no. 1, 167-173.

[8] L. Brown and G. Pedersen, C*-algebras of real rank zero, J. Funct. Analysis. 99, (1991), 138-149.

[9] S. Czerwik, Functional Equations and Inequalities in Several Variables, World Scientific, River Edge, NJ, 2002.

[10] P. Gavruta, A generalization of the Hyers-Ulam-Rassias stability of approximately additive mappings, J. Math. Anal. Appl., 184 (1994), 431-436.

[11] M.E.Gordji, J.M. Rassias, N. Ghobadipour, Generalized Hyers-Ulam stability of the generalized (n, k)-derivations, Abs. Appl. Anal. Volume 2009, Article ID 437931,

[12] M.E.Gordji, S. Kaboli Gharetapeh, M. B. Savadkouhi, M. Aghaei, T. Karimi, On Cubic Derivations, Int. Journal of Math. Analysis, Vol. 4, 2010, no. 51, 2501 - 2514

[13] D.H. Hyers, On the stability of the linear functional equation, Proc.Nat. Acad.Sci.,U.S.A.,27 (1941) 222-224.

[14] D.H. Hyers, G. Isac, Th.M. Rassias, Stability of functional equations in several variables,Birkhauser, Basel, 1998.

[15] K. W. Jun and H. M. Kim, On the stability of an n-dimensional quadratic and additive type functional equation, Math. Ineq. Appl 9(1) (2006), 153-165.

[16] K. W. Jun and D. W. Park, Almost derivations on the Banach algebra $\mathrm{C}^{\mathfrak{n}}[0,1]$, Bull. Korean Math. Soc. 33 (1996), no. 3, 359-366.

[17] K.W. Jun, H.M. Kim, On the Hyers-Ulam-Rassias stability of a generalized quadratic and additive type functional equation, Bull. Korean Math. Soc. 42(1) (2005), 133-148.

[18] K.W. Jun, H.M. Kim, On the stability of an n-dimensional quadratic and additive type functional equation, Math. Ineq. Appl 9(1) (2006), 153-165.

[19] S.M. Jung, Hyers-Ulam-Rassias Stability of Functional Equations in Mathematical Analysis, Hadronic Press, Palm Harbor, 2001.

[20] Y.S. Jung, The Ulam-Gavruta-Rassias stability of module left derivations, J. Math. Anal. Appl., doi: 10.1016/j.jmaa.2007.07.003, 1-9.

[21] Pl. Kannappan, Quadratic functional equation inner product spaces, Results Math. 27, No.3-4, (1995), 368-372. 
[22] Pl. Kannappan, Functional Equations and Inequalities with Applications, Springer Monographs in Mathematics, 2009.

[23] A. Najati, M.B. Moghimi, On the stability of a quadratic and additive functional equation, J. Math. Anal. Appl. 337 (2008), 399-415.

[24] J.M. Rassias, On approximately of approximately linear mappings by linear mappings, J. Funct. Anal. USA, 46, (1982) 126-130.

[25] C. Park, On the stability of the linear mapping in Banach modules, J. Math. Anal. Appl. $275,(2002), 711-720$.

[26] C. Park, Linear functional equation in Banach modules over a $\mathrm{C}^{*}$-algebra, Acta Appl. Math. 77, (2003), 125-161.

[27] C. Park, Linear derivations on Banach algebras, Nonlinear Funct. Anal. Appl. 9 (2004), no. 3, 359-368.

[28] C. Park, Fixed points and Hyers-Ulam-Rassias stability of Cauchy-Jensen functional equation in Banach algebras, Fixed Point Theory and Applications, 2007, Art ID 50175.

[29] C. Park and J. Hou, Homomorphism and derivations in $\mathrm{C}^{*}$-algebras, Abstract Appl. Anal. 2007, Art. Id 80630.

[30] Th.M. Rassias, On the stability of the linear mapping in Banach spaces, Proc.Amer.Math. Soc., 72 (1978), 297-300.

[31] Th.M. Rassias, Functional Equations, Inequalities and Applications, Kluwer Acedamic Publishers, Dordrecht, Bostan London, 2003.

[32] K. Ravi, M. Arunkumar and J.M. Rassias, On the Ulam stability for the orthogonally general Euler-Lagrange type functional equation, International Journal of Mathematical Sciences, Autumn 2008 Vol.3, No. 08, 36-47.

[33] S.M. Ulam, Problems in Modern Mathematics, Science Editions, Wiley, NewYork, 1964. 